\title{
Trends in energy intake among US children by eating location and food source, 1977-2006
}

\author{
Jennifer M. Poti and Barry M. Popkin, PhD \\ Department of Nutrition, University of North Carolina at Chapel Hill
}

\begin{abstract}
Background-Little is known about the impact of location of food consumption and preparation upon daily energy intake for children.

Objective-To examine trends in daily energy intake by children for foods eaten at home or away-from-home, by source of preparation, and for combined categories of eating location and food source.
\end{abstract}

Subjects-The analysis uses data from 29,217 children aged 2-18 years from the 1977-1978 Nationwide Food Consumption Survey, 1989-1991 and 1994-1998 Continuing Survey of Food Intake by Individuals, and 2003-2006 National Health and Nutrition Examination Surveys.

Methods-Nationally representative weighted percentages and means of daily energy intake by eating location were analyzed for trends from 1977 to 2006. Comparisons by food source were examined from 1994 to 2006. Analyses were repeated for 3 age groups: 2-6, 7-12, and 13-18 year olds. Difference testing was conducted using a $t$ test.

Results-Increased energy intake (+179 kcal/d) by children from 1977-2006 was associated with a major increase in calories eaten away-from-home $(+255 \mathrm{kcal} / \mathrm{d})$. The percentage of $\mathrm{kcal} / \mathrm{d}$ eaten away-from-home increased from $23.4 \%$ to $33.9 \%$ from $1977-2006$. No further increase was observed from 1994-2006, but the sources of calories shifted. The percentage of calories from fast food increased to surpass intake from schools and become the largest contributor to foods prepared away-from-home for all age groups. For foods eaten away-from-home, the percentage of kcal/d from stores increased to become the largest source of calories eaten away-from-home. Fast food eaten at home and store-bought food eaten away-from-home increased significantly.

Conclusion-Eating location and food source significantly impact daily energy intake for children. Foods prepared away-from-home, including fast food eaten at home and store-prepared food eaten away-from-home, are fueling the increase in total calorie intake. However, further research using alternative data sources is necessary to verify that store-bought foods eaten awayfrom-home are increasingly store-prepared.

\section{Keywords}

energy intake; eating location; food source; food away-from-home

\footnotetext{
(C) 2011 The American Dietetic Association. Published by Elsevier Inc. All rights reserved.

Corresponding Author, Barry M. Popkin, University of North Carolina, Carolina Population Center, 123 W. Franklin St., Chapel Hill, NC 27516, Tele: 919-966-1732, Fax: 919-966-9159, popkin@unc.edu.

Publisher's Disclaimer: This is a PDF file of an unedited manuscript that has been accepted for publication. As a service to our customers we are providing this early version of the manuscript. The manuscript will undergo copyediting, typesetting, and review of the resulting proof before it is published in its final citable form. Please note that during the production process errors may be discovered which could affect the content, and all legal disclaimers that apply to the journal pertain.
} 


\section{Introduction}

The increase in childhood obesity coincides with a shift in the American diet toward increased consumption of foods eaten and/or prepared outside of the home (1-4). Concerns about the nutritional quality of these foods have placed a great deal of attention upon awayfrom-home foods. The marked rise in the frequency and quantity of away-from-home food consumption, particularly at restaurants and fast food establishments, has been well documented $(4,5)$. For children in particular, the proportion of total calories obtained from all non-home, non-school food sources increased from $9 \%$ in 1977 to $22 \%$ in 1996, with the main source of away-from-home foods shifting from school to fast food (6).

Numerous studies have shown that foods obtained from away-from-home sources have lower nutritional content than foods prepared at home, although further research is needed (4-7). Both increased energy intake and lower diet quality have been associated with awayfrom-home foods $(8,9)$. The lower nutritional content of fast food and its potential negative impact on diet quality have been documented (10-12). Similarly the quality of food purchased at schools has been questioned (5-7, 13-16).

Yet most studies focus on foods prepared away-from-home but not foods consumed awayfrom-home (1-7). Research has largely ignored the combined impact of the location of food consumption and the location of its preparation upon energy intake. Trends in energy intake by eating location have not been previously examined. With increasing consumption of takeout and home delivery combined with a decrease in time spent in food preparation and cooking, these are critical issues to understand $(17,18)$. Furthermore, no research has examined foods obtained from particular sources, such as stores or fast food, by eating location.

This paper systematically examined patterns and trends not only in away-from-home consumption but also in the combination of eating location and food source for US children. This analysis utilized nationally representative survey data for children aged 2 to 18 years to investigate the relationship among eating location, food source, and energy intake within the context of total daily intake. Trends in energy intake were determined for US children overall as well as for three age groups: preschoolers 2 to 6 years old, young children 7 to 12 years old, and adolescents 13 to 18 years old. This study updated previous analyses of energy intake for foods prepared away-from-home and identified trends in energy intake by eating location. This analysis uniquely examined the proportion of store-bought and fast food eaten at home and away-from-home.

\section{Methods}

This study used data on 29,217 children aged 2 to 18 years from four nationally representative surveys of food intake for the U.S. population: 11,499 participants from the 1977 to 1978 Nationwide Food Consumption Survey (NFCS77) (19); 3,122 participants from the 1989 to 1991 Continuing Survey of Food Intake by Individuals (CSFII89) (20); 7,952 participants from the 1994 to 1996 Continuing Survey of Food Intake by Individuals, combined with children ages 2 to 9 surveyed in 1998 (CSFII94) (21); and 6,644 participants from the 2003-2004 and 2005-2006 joint U.S. Department of Agriculture (USDA) National Health and Nutrition Examination Surveys (NHANES03) (22). The surveys were selfweighting, multistage, stratified area probability samples of the U.S. population. Details about each survey have been published previously.

The NFCS77 and CSFII89 surveys collected three consecutive days of dietary intake: one in-home, interviewer-administered 24-h recall and two self-administered one day food intake records. The CSFII94 survey collected two nonconsecutive interviewer-administered 
24-h recalls by phone. NHANES03 collected two nonconsecutive 24-h recalls, with the first day of intake by trained dietary interviewers in the Mobile Examination Center and a second day by telephone interview three to ten days later. These interviews used a fully automated, computer-assisted multiple-pass dietary recall method involving a five step process to probe for potentially forgotten foods. For children 5 years of age and under, a proxy respondent provided dietary information, and interviews for children 6 to 11 were proxy-assisted.

For each survey, only the first two days of dietary intake were used to provide comparable data. Because the third day of dietary intake was collected only in NFCS77 and CSFII89, the third day was not used. The two days of dietary intake collected by CSFII94 and NHANES03 were similar in methods to earlier USDA surveys. To ensure comparability of dietary data and survey weights provided, only participants with both days of dietary intake were included.

\section{Categorization of Location of Consumption and Source of Preparation}

For all surveys, the percentage of energy intake by eating location for each age group of children was determined to examine trends over the past 30 years in eating at home versus eating away-from-home.

Energy intake by location of consumption is the only comparable measure available for all four sets of data. For each food consumed in NFCS77, the respondent was asked if the food came from the home food supply and was eaten at home, came from the home food supply but was eaten outside the home, or was obtained and eaten away-from-home. The source of each food item was only ascertained for foods obtained and eaten away-from-home. Foods obtained outside the home but eaten at home do not clearly fit into any location category of NFCS77. Likewise, for each food item in the CSFII89 survey, the participant was asked whether the food was eaten at home, brought into the home but eaten away-from-home, or never brought into the home. For foods brought into the home, the respondent was asked to describe the food source as from fast food, Meals on Wheels, or another source; these categories do not separate store-bought, restaurant, school, or vending foods. A complete description of food source was only determined for foods never brought into the home. Therefore, NFCS77 and CSFII89 were only used in the analysis of eating location but not for food source.

Both the CSFII94 and NHANES03 surveys asked the respondent separate questions about the location of consumption and source for each food item. These surveys were used in this analysis of energy intake by source of food preparation. Source of preparation was classified as Home/Store, including purchases from grocery, convenience, and drug stores and supermarkets, that are prepared either at the store or in the home; Restaurant, including bars, taverns, lounges, and cafeterias; Fast food, including pizza and carryout places; School, including school cafeterias and child care centers; Vending; and Other, including Meals on Wheels, soup kitchens, other community feeding programs, residential facilities, foods eaten at someone else's home, gifts, and other miscellaneous sources. Definitions of sources were uniform across CSFII94 and NHANES03. Also, categories were combined for eating location and source of preparation to more completely describe each food as eaten at home or eaten away, and prepared at home or prepared away-from-home.

The source of purchase and the source of food preparation are generally the same. However, these surveys did not collect information about whether store-bought foods were prepared at home or fully prepared at the store. Store-bought foods include both "whole" foods prepared at home, such as raw meats that are cooked at home, and ready-to-eat foods prepared at the store, such as fried chicken cooked at a grocery store kitchen. The data for foods from stores do not allow further distinction between whole foods and ready-to-eat prepared foods. 
Therefore, the source of preparation for these foods is indicated as Home/Store. By necessity, store-bought foods are referred to as prepared at home, although we acknowledge that this approach fails to classify store-prepared foods as food prepared away-from-home. Food prepared away-from-home only includes foods from restaurant, fast food, school, vending, and other sources.

For all surveys, respondents were excluded from the study if the energy content of any food item or location of consumption for any energy-providing item was missing from the data set. Participants with only one day of dietary intake were excluded. For CSFII94 and NHANES03, respondents were also excluded if missing the source of preparation for any observation. Of children with dietary and demographic data, the percentages of participants excluded in each survey are 5.2\% in NFCS77, 24.5\% in CSFII89, $11.7 \%$ in CSFII94, and $8.5 \%$ in NHANES03. A larger percentage of children was excluded in CSFII89 because an appropriate weight variable was not available in the survey data.

\section{Statistical Analysis}

Analyses were performed using STATA (version 11, 2009, StataCorp, College Station, TX). Two-day average intakes per person were used to compute mean intake by location across all persons. The STATA survey commands take into account appropriate survey weight factors provided by the USDA for each survey, clustering, and stratification of the survey design. These methods generate results adjusted to be nationally representative of the American population and compensate for survey design effects. Difference testing was conducted using a $t$ test, and a $P$ value $\leq 0.01$ was considered significant.

\section{Results}

Sociodemographic characteristics and unadjusted energy intakes are presented in Table 1. Overall daily energy intake has risen from NFCS77 to NHANES03 (+179 kcal/d, $P<.01)$. By age group, $\mathrm{kcal} / \mathrm{d}$ increased by $241(P<.01), 175(P<.01)$, and $160 \mathrm{kcal}(P<.01)$ for preschoolers ages 2 to 6 , young children 7 to 12 , and adolescents 13 to 18 , respectively, over this time period.

\section{Energy by Location of Consumption}

Figure 1 presents the mean absolute $\mathrm{kcal} / \mathrm{d}$ from at home and away-from-home food and the average proportion of total energy intake consumed at home. From NFCS77 to NHANES03, all age groups of children are eating a smaller percentage of their kcal/d at home. However, the absolute kcal eaten at home decreased only slightly $(-76 \mathrm{kcal} / \mathrm{d}, P<.01$ for ages $2-18)$; the decreased percentage of $\mathrm{kcal} / \mathrm{d}$ consumed at home resulted from the increased total kcal/ d. From NFCS77 to NHANES03, the increase in $\mathrm{kcal} / \mathrm{d}$ resulted mainly from a large increase in calories eaten away-from-home (from 447 to $702 \mathrm{kcal} / \mathrm{d}$ for ages $2-18, P<.01$ ). For young children and preschoolers, increased $\mathrm{kcal} / \mathrm{d}$ resulted only from increased energy consumed away-from-home.

\section{Percentage of Energy by Source of Preparation}

The percentages of $\mathrm{kcal} / \mathrm{d}$ from each source of food preparation are presented in Figure 2 for CSFII94 and NHANES03. In 2006, the main source of energy for children was Home/Store, which provided over two-thirds of total calorie intake $(P<.01)$; only the remaining third of energy intake came from foods prepared away-from-home, which this study defines as any food not purchased from stores. For ages 2-18, the largest contributor to foods prepared away-from-home was fast food, which provided 13\% of total energy intake in $2006(P<.01)$. Schools, restaurants, vending, and other sources provided much smaller percentages of children's energy intake. 
The percentage of calories from stores was much higher for preschoolers $(76 \%)$ than for the older age groups $(P<.01)$. Preschoolers ate the smallest percentage of calories from fast food $(8 \%, P<.01)$, while adolescents had a much higher fast food intake $(17 \%, P<.01)$. From 1994 to 2006, the proportion of energy from store-bought foods remained unchanged for each age group. For children overall, the percentage of kcal/d from fast food increased significantly $(+3 \%, P<.01)$. Intake from restaurants increased slightly while other sources decreased.

\section{Percentage of Energy by Location of Consumption and Preparation Combined Foods Eaten at Home}

When both the location of consumption and of preparation were considered, more complex trends appeared between 1994 and 2006 (Table 2). While the overall proportion of energy intake from foods eaten at home did not change, the sources of these foods did shift. Foods eaten at home, purchased at a store decreased from $62.1 \%$ of daily energy intake for CSFII94 to $57.6 \%$ for NHANES03 for children ages 2 to $18(P<.01)$, while the proportion of energy intake from foods eaten at home, prepared away-from-home increased. The main contributor to this increase was fast food eaten at home, which increased from $3.5 \%$ to $6.1 \%$ of children's overall energy intake $(P<.01)$. Increased calorie intake from fast food eaten at home was observed for each age group.

\section{Foods Eaten Away from Home}

Similarly, from 1994 to 2006, the percentage of calories eaten away-from-home did not change significantly, but the source of these foods shifted. For foods eaten outside the home, the percentage purchased at the store increased from $6.9 \%$ to $11.4 \% \mathrm{kcal} / \mathrm{d}$ for children ages 2 to $18(P<.01)$. Similar increases were observed for all age groups of children.

For children overall, the largest contributor of calories eaten outside of the home changed from school in 1994 (8.7\%) to foods purchased from a store in $2006(11.4 \%)$. This trend was observed for preschoolers and young children. For adolescents, the major contributor to foods eaten away-from-home shifted from fast food (10.9\%) to store foods (11.4\%).

\section{Foods from Stores and Fast Food Establishments}

Stores and fast food are the two major sources of calories for US children. Stores are the largest provider of energy intake for both foods eaten at home and foods eaten away-fromhome $(57.6 \%$ and $11.4 \% \mathrm{kcal} / \mathrm{d}$, respectively, in 2006). The overall contribution of stores to daily energy intake has not changed; however, the proportion eaten away-from-home has increased significantly from $10 \%$ in 1994 to $18 \%$ in 2006, $(P<.01$, Figure 3$)$.

Fast food, the second largest contributor to total energy intake, provides an increasingly significant portion of daily calories, especially for adolescents (17\% kcal/d, Figure 2$)$. In 2006, fast food provided the highest proportion of $\mathrm{kcal} / \mathrm{d}$ from foods prepared away-fromhome for each age group of children. For children ages 2 to 12, the largest contributor to energy intake from foods prepared away-from-home changed from school in 1994 to fast food in 2006. For adolescents, the main source of calories away-from-home was fast food for both time periods. The key shift in fast food from 1994 to 2006 was the location of fast food consumption (Figure 3). The increase in fast food intake arose solely from a significant increase in fast food eaten at home, which increased from $1 / 3$ to almost $1 / 2$ of fast food consumption $(P<.01)$.

\section{Foods from Schools and Vending Machines}

Schools provided only $8 \%$ of total calories for children ages 2 to 18 in 2006 (Figure 2). Both preschoolers and adolescents eat a lower percentage of their daily energy intake from 
schools $(7 \%)$ than young children $(10 \%)$. The percentage of daily energy intake from schools declined from 1994 to 2006, but not significantly $(P=0.09)$.

Vending machines provide only fraction of a percent of total calorie intake for children. This amount did not change significantly from 1994 to $2006(P=0.49)$.

\section{Discussion}

Increased total daily energy intake by children from 1977 to 2006 was associated with a major shift toward increased calories consumed away-from-home $(+255 \mathrm{kcal} / \mathrm{d})$ while the number of calories eaten at home has declined only slightly $(-76 \mathrm{kcal} / \mathrm{d})$. From 1994 to 2006, the sources of food eaten at home and away-from-home have shifted. Stores maintained their role as the predominant source of energy for children, but the proportion of energy from fast food and restaurants increased. Energy intake from school declined. Within this broad shift in children's intake from CSFII94 to NHANES03, important changes occurred in the sources of food consumed at home toward an increasing role for fast foods. For food eaten away-from-home, the increasing calorie intake from store-bought foods drove the overall increase in $\mathrm{kcal} / \mathrm{d}$. In 2006, stores were the largest source of calories for foods eaten at home and for foods eaten away-from-home. A larger percentage of storebought food is eaten away-from-home. When referring to location of preparation, fast food was the largest provider of calories prepared away-from-home in 2006. The increase in fast food intake arose from an increase in fast food consumed at home.

Previous studies demonstrated that children's energy intake increased from 1977 to 1998, but no prior works have examined the energy increase by eating location $(1,2,4,5)$. While the large increase in the percentage of total energy intake derived from away-from-home foods is well documented (1-6), away-from-home foods are defined in these studies as food prepared away-from-home, regardless of eating location. Our analysis by eating location shows that increased energy intake results from an increase in calories consumed awayfrom-home while energy content of foods eaten at home has remained approximately constant. This finding is supported by studies suggesting that overweight individuals do not compensate for increased consumption at away-from-home meals by decreasing intake for the remainder of the day $(8,23)$.

The present study identifies a shift in the source of both foods eaten at home and awayfrom-home for children. Previous studies that describe the decrease from 1977 to 1998 in "home" foods, defined as store-bought foods eaten at home, did not fully illustrate the trends in store-bought foods (1-6). This study shows that the overall intake from stores did not decrease from 1994 to 2006, only the contribution of store-bought foods to intake at home decreased. The overall intake from stores was maintained by a major shift toward increased intake of store-bought foods away-from-home. Previous studies documented a minor role for store-bought foods eaten away-from-home that showed little or no change as a percentage of daily intake from 1977 to 1998 (1).

Of note, this study updates this trend to reveal that the main increase in foods eaten awayfrom-home, and thus in overall energy intake for children, results from a dramatic increase in store-bought foods eaten away-from-home (Table 2: $+4.5 \%$ ). Further studies of storebought foods and their variation in energy density and nutrient composition by location of consumption are warranted to determine the impact of this shift upon energy intake. Storebought "home" food is increasingly ready-prepared, as retail stores are increasing their selection of these "hot-and-ready" choices and spending for these types of foods has increased $(24,25)$. 
However, only the proportion of ready-to-eat foods prepared at restaurants, fast food, schools, and vending machines can be estimated using nationally representative survey data, whereas the percentage of store-bought foods prepared away-from-home cannot be estimated. Thus, the actual proportion of home food versus away-from-home food, as defined by source of preparation, should be evaluated using commercially prepared data sets for store purchases in addition to the NHANES data. Moreover, increases in store-bought, ready-prepared foods should be examined by eating location to evaluate their contribution to the large increase in store-bought foods eaten-away from-home.

Consideration of eating location also revealed more detail about the upward trend in fast food intake. These results agree with prior studies of the increasing role of fast food in children's diets, which is contributing to the major shift toward eating foods prepared awayfrom-home $(1,2,4-6)$. This study is the first to examine the increase in fast food intake by location of fast food consumption. Our study shows that the increase in calories from 1994 to 2006 results entirely from an increase in fast food eaten at home. Almost $1 / 2$ of all fast food calories eaten by children 2 to 18 in 2006 were consumed at home, which represents $6.1 \%$ of all kcal/day. Further studies are needed to examine portion sizes and the contribution of meals versus snacks to fast food purchased as "to go" or drive-thru orders eaten at home.

The role of schools has also changed greatly. While schools were by far the largest awayfrom-home food source in 1977, fast food had increased to become an equal contributor to children's energy intake by $1998(2,6)$. School feeding programs are viewed as a major target for addressing childhood obesity (26-28). Most US public schools participate in the National School Lunch Program and 80\% participate in the School Breakfast Program (14, $15,29,30)$. For preschoolers and young children, school was the largest source of awayfrom-home foods in 1994-98. This study updates this finding for 2006 and shows that fast food has now surpassed school foods as the main away-from-home source of preparation for all age groups of children.

The extremely small percentage of children's energy intake from vending machines is consistent with previous studies (2), yet many school food policies aim to improve children's diets by regulating vending and other "competitive foods" (31-33). While limiting children's access to low-nutrient, energy-dense foods in vending machines may decrease their intake of these items in schools, the impact of removing vending machines on total energy intake appears small but still represents an important education and policy tool $(26,27)$.

Overall, our results suggest that the increases in energy intake by children are fueled by greater consumption of foods prepared away-from-home. The location/source categories showing the greatest increase in \% kcal/d from 1994 to 2006 were fast food eaten at home and store-bought food eaten away-from-home. The increase in store-bought foods eaten away-from-home likely represents an increase in store-prepared foods, and this is a previously unidentified and un-quantified new source of calories prepared away-from-home. As noted, further research is necessary to confirm this assumption. To fully capture increases in foods prepared away-from-home and decreases in home food preparation, future investigations must quantify store-prepared foods.

This study has important limitations, mainly in relation to the use of different dietary surveys. Early methodological changes in diet measurement were addressed by a bridging study, which showed no major shifts in basic eating patterns (34). No problems were reported with results by eating location, so comparisons over all time points are valid. The largest changes in survey methodology occurred between the 1980s and 1990s with the 
introduction of the multiple pass method. No bridging study exists to show the consequences of these methodological changes (35). Although underreporting has increased over time, there is no evidence of bias in reporting by eating location (36). Under-reporting of less healthful foods eaten away-from-home would cause the results presented here to be conservative estimates. Although the same approach was used to collect data for each age group, there is no research about the possible changes over time in parental understanding of child eating patterns. Long-term trends in the location of food preparation were not examined because of the incomplete source information for foods eaten at home collected by NFCS77 and CSFII89.

As noted, the total percentage of energy from foods prepared away-from-home, including those prepared at stores, cannot be measured. By including all store-bought foods within a Home/Store category that is not considered as food prepared away-from-home, storeprepared foods is being improperly considered as home-prepared. The percentage of foods prepared away-from-home is underestimated, and the amount of home-cooking is overestimated. Thus, the increase in $\% \mathrm{kcal} / \mathrm{d}$ from foods prepared away-from-home might be even greater than that estimated by this analysis. Further, no information was collected about how much store-bought, store-prepared food is eaten at the store and how much is eaten at home. Because this study did not assess the quality of foods eaten or obtained away-fromhome, further research is necessary to determine the impact of away-from-home foods upon diet quality. Finally, without information documenting the location of vending machines, foods from vending machines located on school facilities cannot be included in school intake.

\section{Conclusions}

Overall, this study highlights the continuing rapid shifts in the sources of food for children in the US-both where it's eaten and where it's prepared. These results underscore the need to deepen our understanding of food preparation and consumption patterns, and further pinpoint where research and programmatic activity should focus. The differences in energy intake by eating location revealed in this analysis demonstrate that eating location is an important factor in the diet of American children. Further studies of children's diet focusing on energy intake and nutritional quality by eating location are warranted, particularly for store-purchased food overall, carry-out or drive-thru fast food, and hot-and-ready vs. homeprepared foods. Future research should examine the macronutrient distribution of calorie intake by eating location and food source and the impact of body mass index upon such intake. By determining the importance of both where children eat and where their food is prepared, this study helps elucidate where children are obtaining their calories. Because of the increased energy intake and lower nutritional quality associated with away-from-home prepared foods, such insight can be used to focus future efforts to reduce calorie intake and improve dietary quality for American children (4-9).

\section{References}

1. Nielsen SJ, Siega-Riz AM, Popkin BM. Trends in energy intake in U.S. between 1977 and 1996: similar shifts seen across age groups. Obes Res. 2002; 10(5):370-378. [PubMed: 12006636]

2. Nielsen SJ, Siega-Riz AM, Popkin BM. Trends in food locations and sources among adolescents and young adults. Prev Med. 2002; 35(2):107-113. [PubMed: 12200094]

3. Nielsen SJ, Popkin BM. Patterns and trends in food portion sizes, 1977-1998. JAMA. 2003; 289(4): 450-453. [PubMed: 12533124]

4. Lin B, Frazao E, Guthrie J. Contribution of Away-From-Home Foods to American Diet Quality. Fam Econ Nutr Rev. 1999; 12(3/4):85.

5. Lin, B-H.; Frazao, E.; Guthrie, J. Away-From-Home Foods Increasingly Important to Quality of American Diet. United States Department of Agriculture, Economic Research Service; 1999. 
6. Guthrie JF, Lin BH, Frazao E. Role of food prepared away from home in the American diet, 197778 versus 1994-96: changes and consequences. J Nutr Educ Behav. 2002; 34(3):140-150. [PubMed: 12047838]

7. Lin, B.; Guthrie, J.; Blaylock, JR. The diets of America's children: influence of dining out, household characteristics, and nutrition knowledge. Washington, DC: US Dept of Agriculture; 1996.

8. Mancino L, Todd J, Lin B-H. Separating what we eat from where: Measuring the effect of food away from home on diet quality. Food Policy. 2009; 34(6):557-562.

9. Kant AK, Graubard BI. Eating out in America, 1987-2000: trends and nutritional correlates. Prev Med. 2004; 38(2):243-249. [PubMed: 14715218]

10. Sebastian RS, Wilkinson Enns C, Goldman JD. US adolescents and MyPyramid: associations between fast-food consumption and lower likelihood of meeting recommendations. J Am Diet Assoc. 2009; 109(2):226-235. [PubMed: 19167949]

11. Jeffery RW, French SA. Epidemic obesity in the United States: are fast foods and television viewing contributing? Am J Public Health. 1998; 88(2):277-280. [PubMed: 9491022]

12. Bowman SA, Gortmaker SL, Ebbeling CB, Pereira MA, Ludwig DS. Effects of fast-food consumption on energy intake and diet quality among children in a national household survey. Pediatrics. 2004; 113(1 Pt 1):112-118. [PubMed: 14702458]

13. Stallings, VA.; Yaktin, AL., editors. Nutrition Standards for Foods in Schools: Leading the Way toward Healthier Youth. Washington DC: National Academy Press; 2007. Committee on Nutrition Standards for Foods in Schools.

14. Clark MA, Fox MK. Nutritional quality of the diets of US public school children and the role of the school meal programs. J Am Diet Assoc. 2009; 109 Suppl 1(2):S44-S56. [PubMed: 19166672]

15. Crepinsek MK, Gordon AR, McKinney PM, Condon EM, Wilson A. Meals offered and served in US public schools: do they meet nutrient standards? J Am Diet Assoc. 2009; 109 Suppl 1(2):S31S43. [PubMed: 19166671]

16. Briefel RR, Wilson A, Gleason PM. Consumption of low-nutrient, energy-dense foods and beverages at school, home, and other locations among school lunch participants and nonparticipants. J Am Diet Assoc. 2009; 109 Suppl(2):S79-S90. [PubMed: 19166676]

17. Bowers DE. Cooking trends echo changing roles of women. Food Rev. 2000; 23(1):23.

18. Jekanowski MD. Causes and consequences of fast food sales growth. Food Rev. 1999; 22(1):11.

19. Rizek R. The 1977-78 Nationwide Food Consumption Survey. Fam Econ Rev. 1978; 4:3-7.

20. U.S. Department of Agriculture ARS BHNRC, Food Surveys Research Group Continuing survey of food intakes by individuals 1989-91 and diet and health knowledge survey 1989-91:

Documentation (csfii8991_documentation.pdf). Retrieved 05/06/2009 from USDA Agricultural Research Service, Food Surveys Research Group website: http://www.ars.usda.gov/Services/docs.htm?docid=14541. Beltsville, MD: 1989-91.

21. U.S. Department of Agriculture ARS BHNRC, Food Surveys Research Group Continuing survey of food intakes by individuals 1994-96, 1998 and diet and health knowledge survey 1994-96: Documentation (csfii9498_documentationupdated.pdf). Retrieved 05/06/2009 from USDA Agricultural Research Service, Food Surveys Research Group website: http://www.ars.usda.gov/Services/docs.htm?docid=14521. Beltsville, MD:

22. What we eat in America, NHANES 2005-2006. Beltsville, MD: N. C. f. H. S. U.S. Department of Health and Human Services CfDCaP; 2005. U.S. Department of Agriculture ARS BHNRC, Food Surveys Research Group; p. 2005-2006.Available from: http://www.cdc.gov/nchs/about/major/nhanes/nhanes2005-2006/dr1tot_c.xpt

23. Ebbeling CB, Sinclair KB, Pereira MA, Garcia-Lago E, Feldman HA, Ludwig DS. Compensation for energy intake from fast food among overweight and lean adolescents. JAMA. 2004; 291(23): 2828-2833. 2004. [PubMed: 15199032]

24. Tillotson JE. Our ready-prepared ready-to-eat nation. Nutr Today. 2002; 37(1):36-38. [PubMed: 11984431]

25. Jekanowski MD. Grocery industry courts time-pressed consumers with home meal replacements. Food Rev. 1999 
26. Story M, Kaphingst KM, French S. The role of schools in obesity prevention. Future Child. 2006; 16(1):109-134. [PubMed: 16532661]

27. Story M, Kaphingst KM, Robinson-O'Brien R, Glanz K. Creating healthy food and eating environments: policy and environmental approaches. Ann Rev Public Health. 2008; 29(1):253272. [PubMed: 18031223]

28. Story M, Nanney MS, Schwartz MB. Schools and obesity prevention: creating school environments and policies to promote healthy eating and physical activity. Milbank Quarterly. 2009; 87(1):71-100. [PubMed: 19298416]

29. Gordon AR, Cohen R, Crepinsek MK, Fox MK, Hall J, Zeidman E. The third school nutrition dietary assessment study: background and study design. J Am Diet Assoc. 2009; 109 Suppl 1(2):S20-S30. [PubMed: 19166670]

30. Gordon AR, Devaney BL, Burghardt JA. Dietary effects of the National School Lunch Program and the School Breakfast Program. Am J Clin Nutr. 1995; 61(1):221S-231S. [PubMed: 7832169]

31. Fox MK, Gordon A, Nogales R, Wilson A. Availability and consumption of competitive foods in US public schools. J Am Diet Assoc. 2009; 109 Suppl 1(2):S57-S66. [PubMed: 19166673]

32. Templeton SB, Marlette MA, Panemangalore M. Competitive foods increase the intake of energy and decrease the intake of certain nutrients by adolescents consuming school lunch. J Am Diet Assoc. 2005; 105(2):215-220. [PubMed: 15668677]

33. O'Toole TP, Anderson S, Miller C, Guthrie J. Nutrition services and foods and beverages available at school: Results from the School Health Policies and Programs Study 2006. J Sch Health. 2007; 77(8):500-521. [PubMed: 17908105]

34. Guenther, P.; Perloff, B. Washington: U.S. Department of Agriculture, Human Nutrition Information Service; 1990. Effects of procedural differences between 1977 and 1987 in the Nationwide Food Consumption Survey on estimates of food and nutrient intakes: Results of the USDA 1988 Bridging Study. Nationwide Food Consumption Survey 1987-88, NFCS Rep. no. 87.

35. Guenther PM, Perloff BP, Vizioli TL Jr. Separating fact from artifact in changes in nutrient intake over time. J Am Diet Assoc. 1994; 94(3):270-275. [PubMed: 8120290]

36. Heitmann BL, Lissner L, Osler M. Do we eat less fat, or just report so? Int J Obes Relat Metab Disord. 2000; 24(4):435. [PubMed: 10805500] 


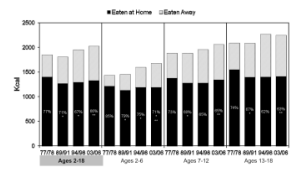

Figure 1.

Daily Energy Intake by Location of Consumption, 1977-78 to 2003-06a

a Data are presented with each bar representing the total mean kcal/d for the age group of children and survey specified, divided into kcal/d eaten at home and eaten away-from-home. Percentages indicate the $\% \mathrm{kcal} / \mathrm{d}$ eaten at home. Data were obtained from Nationwide Food Consumption Survey (NFCS) 1977-78 (n=11499), Continuing Survey of Food Intake by Individuals(CSFII) 1989-91 ( $\mathrm{n}=3122)$, CSFII 1994-98 $(\mathrm{n}=7952)$, and National Health and Nutrition Examination Surveys (NHANES) 2003-06 ( $\mathrm{n}=6644)$.

*Percentage of energy from food eaten at home was significantly different from the previous survey for the specified age group, $\mathrm{P} \leq 0.01$ ( $\mathrm{t}$ test)

**Percentage of energy from food eaten at home was significantly different from 1977-78 to 2003-06 for the specified age group, $\mathrm{P} \leq 0.01$ ( $\mathrm{t}$ test) 


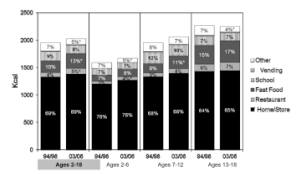

Figure 2.

Daily Energy Intake by Source of Preparation, 1994-98 to 2003-06a

aData are presented with each bar representing the total mean kcal per day for the age group of children and survey specified, divided into mean kcal per day from each source of food preparation. Percentages indicate the $\% \mathrm{kcal} / \mathrm{d}$ from each food source. Data were obtained from CSFII 1994-98 ( $\mathrm{n}=7952)$ and NHANES 2003-06 ( $=6644)$.

bVending contributed less than $1 \% \mathrm{kcal} / \mathrm{d}$ for all age groups and surveys.

${ }^{\mathrm{c}}$ Source of preparation for store-bought foods is marked as Home/Store to indicate that the available data cannot distinguish between store-bought foods that are prepared at home and store-bought foods that are fully store-prepared at purchase.

*Percentage of energy was significantly different from 1994-98, $\mathrm{P} \leq 0.01$ ( $\mathrm{t}$ test) 


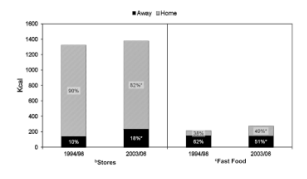

Figure 3.

Daily Energy Intake from Store-bought Food and Fast Food by Eating Location at home and Away-from-Home, Ages 2-18, 1994-98 to 2003-06a,

a Data were obtained from CSFII 1994-98 ( $\mathrm{n}=7952)$ and NHANES 2003-06 ( $\mathrm{n}=6644)$.

${ }^{b}$ Data are presented as absolute kcal per day eaten from store-bought foods by children ages 2-18 for the specified survey. Each bar represents mean kcal from store-bought foods, divided by eating location away-from-home or at home. Percentages indicate the percent of kcal from store-bought foods eaten away-from-home or at home. Store-bought foods cannot be further distinguished as prepared at home or prepared at the store.

${ }^{\mathrm{c}}$ Data are presented as absolute kcal per day eaten from fast food establishments for children ages 2-18 for the specified survey. Each bar represents mean kcal from fast food per day, divided by eating location away-from-home or at home. Percentages indicate the percent of $\mathrm{kcal}$ from fast foods eaten away-from-home or at home.

* Percentage of energy was significantly different from 1994-98, $\mathrm{P} \leq 0.01$ (t test) 


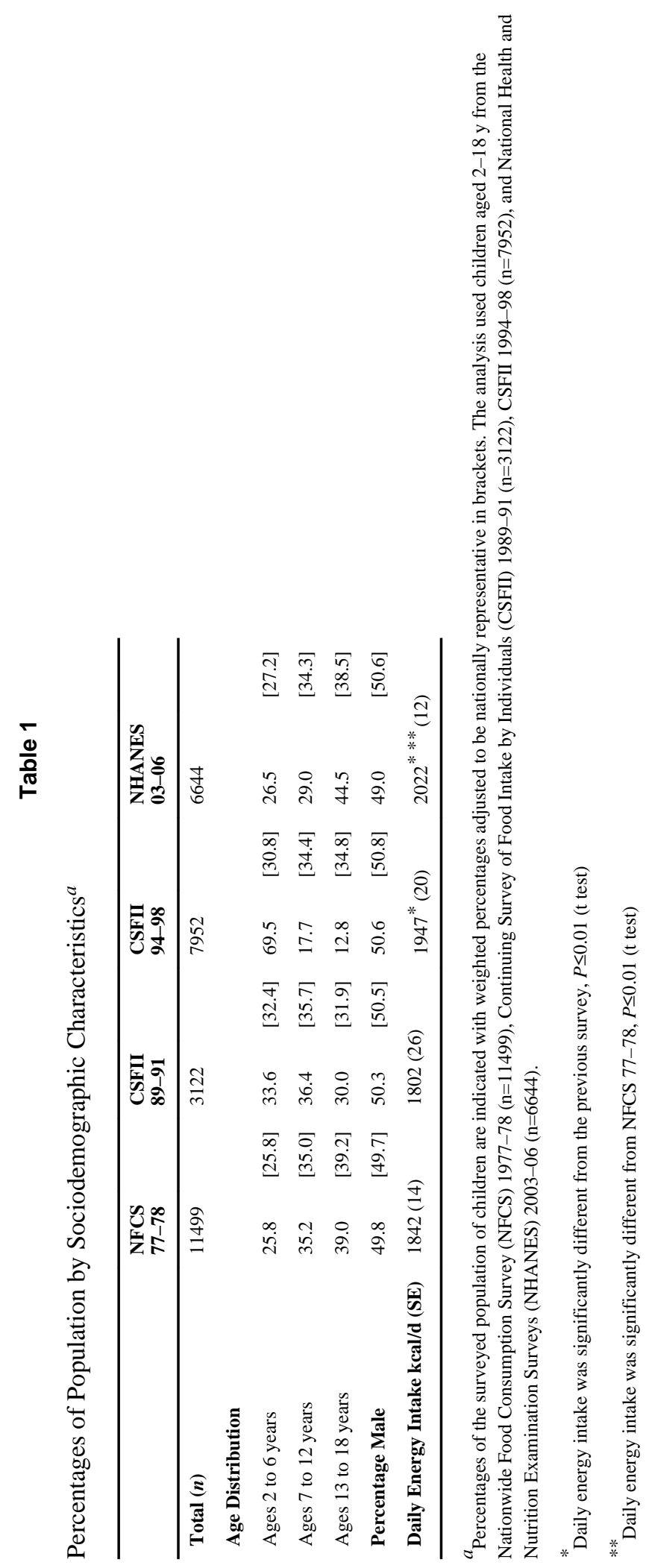




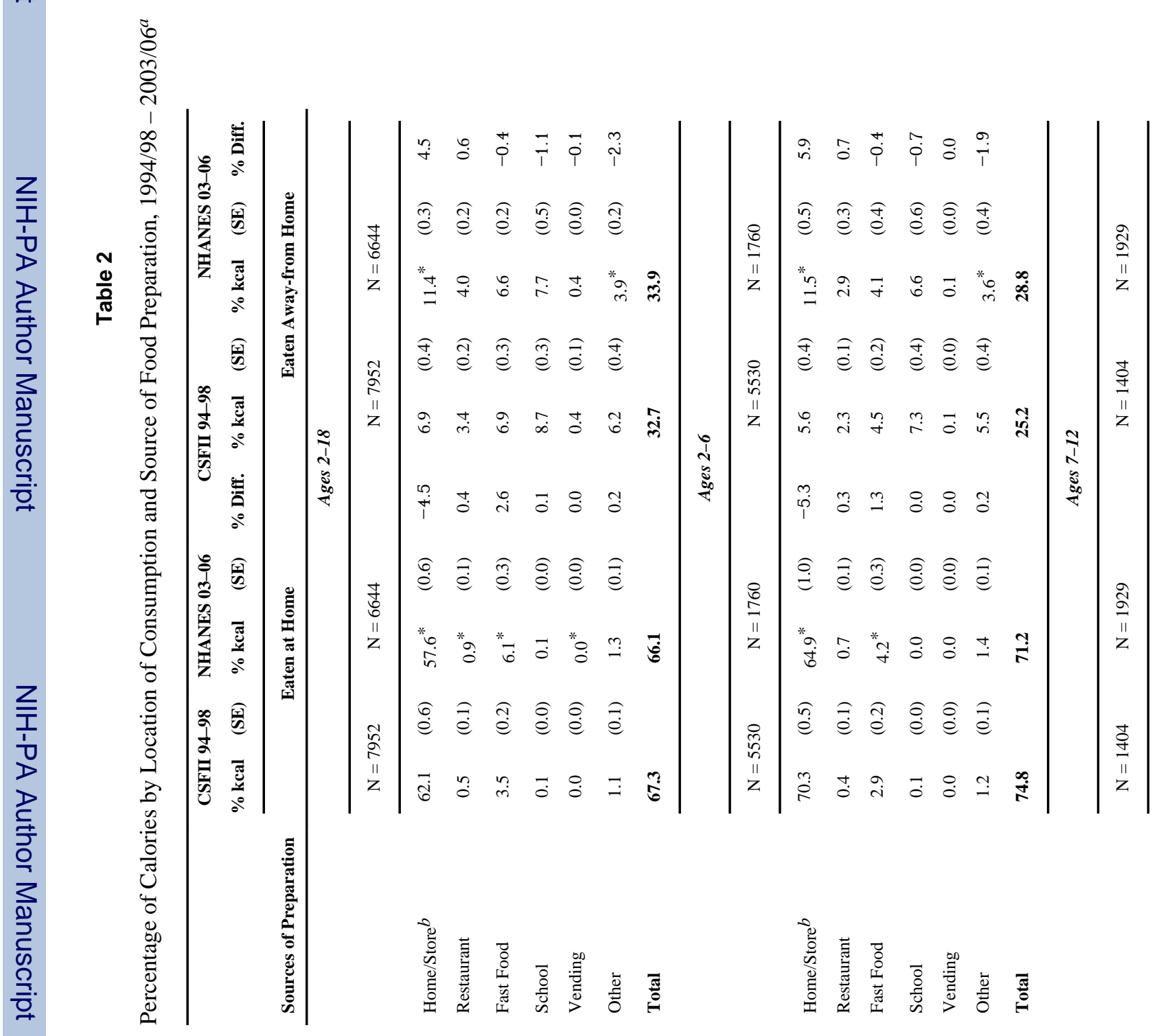


